Vol. 2, n. 3 - Edição Especial: Ciclos Formativos em Ensino de Ciências.

\title{
Experiências vivenciadas durante a abordagem sobre os alimentos e o sistema digestivo em aulas de $8^{a}$ série do ensino fundamental
}

\author{
Experiences lived during the approach to food and the digestive system in \\ the 8th grade of elementary school
}

\author{
Caroline Luana Lottermann Hilgert (caroline_lottermann@ @otmail.com) \\ Rede Municipal de Ensino de Santo Ângelo/RS, Brasil
}

\begin{abstract}
Resumo: O relato contempla discussões acerca das experiências vivenciadas durante a abordagem sobre os alimentos e o sistema digestivo em aulas de Ciências da $8^{\mathrm{a}}$ série do ensino fundamental. Para que fosse possível o entendimento do sistema digestivo como um todo, diferentes aspectos foram abordados tais como: órgãos do sistema digestivo, funções específicas do referido sistema, o que são alimentos e o que os constitui, análise e interpretação de rótulos de alimentos e análise do cardápio da merenda escolar. Os resultados retrataram um interesse dos estudantes na temática proposta, mas, ao mesmo tempo observou-se que estes desconhecem totalmente sobre o que constitui os alimentos e não tem o hábito de fazer a leitura dos rótulos do que consomem. Nesse sentido, destaca-se a importância da abordagem dos conteúdos de forma a integrá-los com as vivências diárias dos estudantes, para que consigamos estimular neles novos hábitos e rotinas, que venham a melhorar o seu dia a dia e colaborar para a transformação de suas realidades para melhor.
\end{abstract}

Palavras-chave: Alimentos, Ciências Naturais, Sistema Digestivo

\begin{abstract}
The report contemplates discussions about the experiences lived during the approach to food and the digestive system in the 8th grade science classes of elementary school. In order to understand the digestive system as a whole, different aspects were addressed such as: organs of the digestive system, specific functions of the digestive system, what is food and what constitutes it, analysis and interpretation of food labels and analysis of the school's lunch menu. The results demonstrated an interest from the students in the proposed topic, however, it was also observed that they were totally unaware of what constitutes food and do not have the habit of reading the labels of what they consume. Thereby, the importance of approaching topics in such a way to integrate them in the students' daily experiences is emphasized, as a result we can stimulate new habits and routines that will improve their daily life and collaborate for the transformation of their realities, for the better.
\end{abstract}

Keywords: Food, Natural Sciences, Digestive System 


\section{Vol. 2, n. 3 - Edição Especial: Ciclos Formativos em Ensino de Ciências.}

\section{CONTEXTUALIZAÇÃO}

O presente relato busca sistematizar e refletir algumas atividades desenvolvidas no âmbito da sala de aula na disciplina de Ciências, com estudantes da $8^{a}$ série do ensino fundamental de uma escola da rede pública municipal de Santo Ângelo. Tais atividades referiram-se ao estudo do Sistema Digestivo, conteúdo este que integra o plano de estudos de Ciências para a $8^{\mathrm{a}}$ série do município de Santo Ângelo.

Pensar e buscar entender o funcionamento do aparelho digestivo me remete, de imediato, a necessidade de compreender sobre os alimentos, afinal, "só ocorre digestão porque ingerimos alimentos”. Para nós professores essa frase é obvia e nos parece até mesmo desnecessário mencioná-la, no entanto, nossos estudantes de $8^{\text {a }}$ série nem sempre conseguem estabelecer tais relações com tanta facilidade e clareza. Daí a importância e necessidade de abordagem eficiente e ampla sobre a temática dos alimentos, para que, sabendo um pouco mais sobre o que ingerem, sejam capazes de compreender a lógica de funcionamento de seu sistema digestivo.

Para que os estudantes pudessem chegar a esse entendimento do "todo", vários aspectos foram trabalhados. As discussões sobre o sistema digestivo iniciaram com a abordagem e questionamentos sobre a importância dos alimentos para os seres vivos e logo após conversamos sobre o que constitui os diferentes alimentos que ingerimos. Ao abordar que os alimentos são formados por diferentes nutrientes e que estes precisam ser reduzidos em unidades menos para que nosso organismo seja capaz de aproveitá-los, passamos a discutir e observar, em mapas e no livro didático disponível na escola, os diferentes órgãos e estruturas que são fundamentais para que ocorra a digestão.

O tempo destinado ao estudo dos órgãos bem como suas funções foi curto, afinal, o principal objetivo que havia traçado para essa temática era o de fazer com que eles soubessem mais sobre "o que constitui os alimentos"; "o porquê da importância de nos alimentarmos bem"; "como saber o que estamos ingerindo"; "o que querem dizer os rótulos dos alimentos"; "por que algumas pessoas não podem ingerir alguns tipos de alimentos"; "o que é a pirâmide alimentar" e "o porquê de termos um cardápio de merenda escolar organizado de tal forma na escola". 


\section{Vol. 2, n. 3 - Edição Especial: Ciclos Formativos em Ensino de Ciências.}

\section{DESCRIÇÃO E ANÁLISE DAS ATIVIDADES}

Para que os entendimentos sobre a temática de fato fossem efetivados, foram desenvolvidas algumas atividades em sala de aula, as quais estão descritas abaixo.

\section{1 - O que constitui os alimentos?}

Após nossa fala inicial sobre a função e importância do processo de digestão, no sentido de que é por meio deste que os alimentos são reduzidos em unidades menores para que possam ter seus nutrientes absorvidos, se fez necessário compreender eu nutrientes são esses e quais as diferentes funções que desempenham em nosso organismo. Com o auxílio do livro didático, foram realizadas leituras e sistematização de conceitos no caderno sobre os diferentes grupos de nutrientes.

Em relação aos carboidratos, conversamos sobre os diferentes tipos de açúcares que constituem nossos alimentos (amido, celulose, sacarose, maltose, frutose, glicose entre outros), sobre quais elementos químicos constituem essas moléculas e a função energética atribuída aos carboidratos.

Foi possível perceber durante nossa leitura e discussão que o termo "açúcar" remetia apenas a idéia de doce ou usado para adoçar. Grande parte dos estudantes não sabia que o amido era um açúcar e que as frutas apresentam um tipo de açúcar denominado frutose. A partir daí, buscamos conceituar e entender um pouco mais sobre as características de um monossacarídeo, dissacarídeo e polissacarídeo e que nosso organismo é capaz de absorver os carboidratos em sua forma mais simples, de monossacarídeo. Sabendo isso, ficou clara a necessidade de transformação dos carboidratos pela digestão para que possam ser aproveitados pelo nosso organismo.

Em relação aos lipídios, foi abordado que estes podem ser de origem a animal ou vegetal e que estão presentes na banha de porco, na manteiga, e em todos os óleos de origem vegetal (óleo de soja, girassol, canola, azeite de oliva entre outros). Abordamos ainda sobre sua função energética bem como os problemas que a ingestão, em excesso, de determinados tipos de gordura podem causar. 


\section{Vol. 2, n. 3 - Edição Especial: Ciclos Formativos em Ensino de Ciências.}

Sobre as proteínas, além de trabalhar sobre sua função na formação e desenvolvimento do corpo e na reconstituição de tecidos e os alimentos ricos em proteínas, foi abordado sobre as pequenas unidades (aminoácidos) que se ligam e constituem as proteínas. Ao compreender isso, voltamos às discussões sobre a função da digestão, para a transformação dessas moléculas grandes em unidade menores que são capazes de ser absorvidas pelas células do nosso organismo.

Para finalizar, pesquisamos sobre as funções e importância da água, sais minerais e vitaminas para o nosso organismo, bem como os alimentos ricos em tais nutrientes.

\section{2 - Como saber o que estamos ingerindo e o que querem dizer os rótulos dos alimentos?}

Para que pudéssemos responder a essas duas perguntas, no início do nosso trabalho sobre os alimentos, solicitei que os estudantes guardassem todos os tipos de rótulos de alimentos que eram consumidos em casa. Foram trazidos rótulos dos mais diversos alimentos e bebidas para a realização do trabalho de análise e entendimento das informações que constam neles.

Realizamos assim, durante algumas aulas, a análise da tabela de informação nutricional, presente em todos os rótulos, bem como algumas informações adicionais e fundamentais presentes neles.

Sobre a tabela de informação nutricional, a primeira informação analisada foi sobre a porção a qual se referem aquelas informações. Quase que 100\% dos estudantes afirmaram não olhar as informações que constam na tabela de informações nutricionais, prática também não adotada por muitos de nós, adultos. Destacaram também que imaginavam que aqueles valores que constavam nas tabelas se referiam a quantidade de proteínas, açúcares, gorduras presentes na embalagem toda. Nesse momento passamos a analisar mais a fundo esse aspecto, e cada um deles, com diferentes rótulos em mãos, passou a analisar e anotar esses valores. Ao final dessa tarefa demonstraram bastante espanto em descobrir as quantidades excessivas de gordura e açúcar que ingeriam ao consumir biscoitos, salgadinhos e refrigerantes diariamente, bem como as baixas quantidades de vitaminas presentes nestes, o que pode acarretar inúmeros problemas de saúde. 


\section{Vol. 2, n. 3 - Edição Especial: Ciclos Formativos em Ensino de Ciências.}

Passamos também a analisar algumas informações adicionais presentes nos rótulos como, por exemplo, a presença ou não de informação aos alérgicos ou intolerantes a algum dos constituintes do alimento. Em todos os rótulos essas informações estavam presentes.

Além das informações acima observadas, os estudantes visualizaram em alguns rótulos um símbolo desconhecido por eles, um triângulo amarelo com a letra $\mathrm{T}$ no centro. Sugeri que fizessem uma pesquisa na internet para tentarmos descobrir o que significava. Após alguns minutos já tinham a resposta, se tratava da indicação de que "naquela farinha de milho" havia sido utilizado milho transgênico para sua produção. Um dos estudantes ainda fez a consideração de que aquele símbolo era obrigatório no caso dos alimentos que contivessem transgênicos, e que esta era do ano de 2003. Destacou que não sabia de sua existência, que nunca havia reparado esse símbolo nos rótulos de salgadinhos e outros alimentos e que achava bem importante que essas informações estivessem presentes nos alimentos, assim como aquelas aos alérgicos e intolerantes, pois dessa forma a pessoa pode escolher aquilo que deseja consumir bem como evitar alimentos que possam lhe causar problemas de saúde.

Outra estudante disse que a partir de então passaria a olhar mais para o rótulo daquilo que fosse consumir e comprar, a fim de analisar se o alimento seria o mais indicado para o consumo nas diferentes horas do dia (café, almoço, lanche, jantar) e em que quantidade deveria ingeri-lo, para evitar o consumo excessivo de nutrientes que podem ser prejudiciais ao organismo.

Ao ouvir essas frases senti-me bastante realizada e com o sentimento de ter contribuído para ampliar a visão e conhecimentos deles em relação àquilo que consomem, tendo a certeza de que agora eram capazes que analisar e interpretar algumas informações básicas, mas muito relevantes do ponto de vista da saúde, e que seriam capazes de fazer boas escolhas ou pelo menos estar um pouco mais conscientes em relação às escolhas na hora de se alimentar.

\section{3 - Por que precisamos nos alimentar bem? O cardápio da merenda escolar:}

Ao planejar as atividades e discussões sobre as alimentos e sistema digestivo, me perguntei: "será que os alunos sabem por que existe um cardápio escolar e o porquê da 


\section{Vol. 2, n. 3 - Edição Especial: Ciclos Formativos em Ensino de Ciências.}

necessidade de organização daquilo que se come?". Grande parte deles sequer me respondeu, mas, uma aluna me disse que achava que o cardápio servia para organizar aquilo que era importante que eles ingerissem nessa fase da vida em que se encontram.

De fato, esse é um dos principais objetivos da organização do cardápio escolar no Município de Santo Ângelo. Pensado mensalmente por uma nutricionista, o cardápio escolar é o mesmo para todas as escolas da rede municipal de Santo Ângelo e tem como objetivo oferecer aos estudantes os nutrientes fundamentais para o seu crescimento e desenvolvimento físico e intelectual.

Para entender um pouco sobre a forma de organização desse cardápio, a turma foi dividida em grupos. Cada Estudante recebeu uma cópia do cardápio escolar do mês de julho, o qual é de domínio público e está fixado no mural principal da escola e no refeitório. Foram feitas algumas perguntas para orientar o trabalho de análise.

- Quantas vezes na semana temos comida "de sal"?

- Quantas vezes na semana temos lanche?

- Com que freqüência, na semana, é oferecido saladas e frutas?

- Em cada uma das refeições, que grupos de nutrientes estão presentes e qual sua função?

Os estudantes observaram que durante a semana, por três vezes são preparados alimentos "de sal" e duas vezes há lanche. Saladas, frutas e legumes estão presentes quase que diariamente na alimentação oferecida na escola e que os alimentos são organizados dessa forma para que proteínas, carboidratos, lipídios, vitaminas e sais minerais estejam presentes nas quantidades necessárias para atender as necessidades nutritivas essenciais para o crescimento e desenvolvimento do corpo, fornecimento de energia e bom desempenho das atividades vitais nessa fase da vida.

Conversamos sobre a importância de realizar o lanche na escola, já que, durante a manhã, grande quantidade de energia era gasta para estudar, realizar atividades físicas propostas em aula, brincar, e por isso, se faz necessários fornecer energia ao nosso organismo, que vem dos alimentos. As conclusões sobre a análise do cardápio escolar foram sistematizadas em um cartaz, fixado no mural da escola. 


\section{Vol. 2, n. 3 - Edição Especial: Ciclos Formativos em Ensino de Ciências.}

Após a realização das atividades, organizamos uma mesa redonda como forma de avaliar as atividades desenvolvidas e ouvir um pouco sobre o que acharam do trabalho e temática. Dos estudantes que se manifestou, grande maioria destacou a importância de aprender sobre os alimentos, sabendo interpretar o que está escrito nos rótulos e tabelas de informação nutricional, como forma de conhecer um pouco mais sobre o que consomem e, assim, ser capaz de decidir por aquilo que é importante comer e que será fundamental para o seu crescimento e desenvolvimento. Alguns também acharam importante o trabalho de análise do cardápio escolar, passando a compreender que os alimentos oferecidos diariamente na escola são pensados por um profissional especializado e com a finalidade de atender necessidades fundamentais do organismo.

\section{CONCLUSÃO}

Ao concluir e avaliar as atividades desenvolvidas sobre a temática tenho cada vez mais certeza da necessidade de discutir e trazer para a sala de aula assuntos e temas de nossa vivência diária, das coisas que comemos todos os dias, nesse caso. Nesse sentido, cabe destacar a importância da escola, instituição que tem como finalidade específica a promoção e a aquisição do conhecimento universalmente construído, a transmissão cultural (YONG, 2007).

De acordo com Michael Young, a instituição escolar permite e capacita os jovens "a adquirir o conhecimento que, para a maioria deles, não pode ser adquirido em casa ou em sua comunidade, e para os adultos, em seus locais de trabalho" (2007, p. 1294). Esse conhecimento é chamado pelo autor de "conhecimento poderoso" e se refere àquilo que o conhecimento possibilita ao sujeito, seja naquilo que pode fazer ao ter acesso à eles, ou no sentido de fornecer novas ideias e possibilidades de pensar e de agir no mundo (YOUNG, 2007).

O “conhecimento poderoso" é o conhecimento de caráter escolar. Sendo assim, é especializado, específico e adquirido na escola: instituição com intenção específica, com forma proposital, que é a de promover a aprendizagem de saberes específicos a cada área do conhecimento, além da aprendizagem de valores e atitudes, a partir de atividades desenvolvidas na instituição escolar. Além do mais, tem por função trabalhar com saberes historicamente construídos e aparece quando é preciso ensinar/aprender um 


\section{Vol. 2, n. 3 - Edição Especial: Ciclos Formativos em Ensino de Ciências.}

saber científico, diferente daquele aprendido em casa, na comunidade ou na rua (SAVATER, 1998).

Por esse motivo, se faz importante discutir e relacionar aos conteúdos escolares assuntos e dúvidas da realidade diária dos estudantes, para que o conhecimento específico tenha sentido e possa ser aprendido e aproveitado por eles durante toda sua vida, além de possibilitar que se tornem mais críticos em relação ao que ouvem e sejam capazes de fazer as escolhas certas para uma vida de sucesso.

\section{REFERÊNCIAS}

SAVATER, Fernando. O valor de Educar. São Paulo: Martins Fontes, 1998.

YOUNG, Michael. Para que servem as Escolas? Educ. Soc., Campinas, vol. 28, n. 101, p. 1287-1302, set./dez. 2007. Disponível em: http://www.cedes.unicamp.br. Acesso em: 25 de nov. de 2018. 